DOI: $10.22616 /$ foodbalt.2017.036

\title{
DEVELOPMENT OF NUTRITIVE SNACKS: KIWI BARS
}

\author{
Raquel P. F. Guine ${ }^{1 *}$, Salome Seabra ${ }^{2}$ \\ ${ }^{I *}$ CI\&DET Research Centre and Food Industry Department, Polytechnic Institute of Viseu, Viseu, Portugal, \\ e-mail: raquelguine@esav.ipv.pt \\ ${ }^{2}$ Department of Food Industry, Agrarian School, Polytechnic Institute of Viseu, Viseu, Portugal
}

\begin{abstract}
Presently there is an increasing concern about not wasting any type of product with potential commercial utility, like food waste. Thus, this work was undertaken in collaboration with a company in order to find a nutritionally interesting form of valorisation of kiwi waste, namely the pulp from fruits not compliant with commercial standards (like size or shape).

Based on the proposed aims, kiwi based snacks (bars) were developed from kiwi pulp with the addition of gelling agents and some other ingredients. The product development was an intensive task, with multiple experiments until the desired characteristics could be achieved. Because the company intends to commercialize the bars it was also necessary to make a sensory evaluation, to assess the opinion about the developed product(s). Two final products were obtained: a simple kiwi bar and a bar with nuts and oat.

Based on the results obtained it was possible to conclude that, at the nutritional level, the bars revealed low values of energy and carbohydrates, which is positive because nowadays foods with low caloric density and little sugar are valued. Moreover the values of fibre and minerals were high, thus bringing added nutritional advantages.

Through sensory evaluation it was possible to understand that the simple kiwi bar was preferred by the panellists. Colour evaluation showed that the simple kiwi bar had more intense yellow and green colourations as compared to the other bar. Also textural results showed that the simple kiwi bar was softer, more elastic and more cohesive.
\end{abstract}

Keywords: chemical properties, nutritional properties, physical properties, sensory analysis.

\section{Introduction}

The kiwi fruit (Actinidia deliciosa) is original from Asia but today is widely consumed all around the world due to its sensory and nutritional properties (Soquetta et al., 2016).

Kiwi was domesticated in New Zealand in the beginning of the nineteenth century, and then reintroduced for commercial production in China (Lu et al., 2016). Widely consumed, kiwi fruit has many cultivars and is nowadays produced in many diverse regions of the globe. Nevertheless, cultivar variability is quite important because different cultivars grown in the same geographic and climatic conditions show significant differences in their nutritive and bioactive properties (Park et al., 2014).

Kiwi fruit is rich in fibre, minerals and bioactive compounds with antioxidant capacity, which are phytochemicals that act as scavengers of free radicals, or prevent their formation. Kiwi is considered a fruit with high nutritional value because of the high vitamin $\mathrm{C}$ content and antioxidant capacity (Le, Knulst, 2015; Soquetta et al., 2016).

The fruit marketing and processing industry generates important quantities of residues, which could pose environmental problems as well as economic losses. The utilization of off-size fruits and residues constitutes therefore a necessity to minimize harmful impacts. In this way, by-products of kiwi fruit can contribute to the reduction of agro-industrial waste (Sharma et al., 2016; Soquetta et al., 2016).

The aim of this research was to develop new food products (snacks in the form of bars) made from kiwi pulp as a form of valorisation of the fruits not compliant with commercial standards. Moreover, it was intended to obtain products with a balanced and improved nutritional composition to provide bioactive properties.

\section{Materials and Methods}

Fruits of the cultivar Hayward were provided by the company KiwiCoop (Mealhada, Portugal).

For the preparation of the bars the ingredients used were kiwi pulp and juice, pectin (Sigma-76282 from SigmaAldrich; Mr 30000-100000), agar-agar (granulated, CAS 9002-18-0 from Merck), sugar, oat, and walnut.

For the development of the new food products many experiments were made until the desired properties would be found. At last, two products were made, according to the formulations shown in Table 1.

Table 1

Kiwi bars formulation

\begin{tabular}{lcc}
\hline Ingredient & $\begin{array}{c}\text { Simple Kiwi } \\
\text { Bar (SKB) }\end{array}$ & $\begin{array}{c}\text { Kiwi bar } \\
\text { with walnut } \\
\text { (KBW) }\end{array}$ \\
\cline { 2 - 3 } g per bar \\
\hline Kiwi pulp & g per bar & 26.5 \\
Kiwi juice & 26.3 & 30.2 \\
Pectin & 25.8 & 2.0 \\
Agar-agar & 2.0 & 1.3 \\
Sugar & 1.1 & 4.2 \\
Walnut + Oat mix & 4.2 & 5.9 \\
\hline
\end{tabular}

The analyses made to the kiwi bars were moisture content (by drying to constant weight), crude fibre (by digestion acid/basic using Dosi-Fiber), crude protein (by Kjeldhal method, mineralization of protein), ash (by incineration at $550{ }^{\circ} \mathrm{C}$ ) and ascorbic acid (by titration with 2,6-dicloroindofenol) following standard procedures (AOAC, 2012). Acidity was determined by titration following the Portuguese Standard NP-1421. Carbohydrates were determined by difference.

Colour was evaluated by a colorimeter CR-400 (Konica Minolta) in the CIELAB colour space: $\mathrm{L}^{*}=$ lightness, $\mathrm{a}^{*}=$ green $/ \mathrm{red}, \mathrm{b}^{*}=$ blue $/$ yellow (Guiné et al., 2015). 
Texture was evaluated by texture profile analysis (TPA) with a texturometer TA.XT Plus (Stable Micro Systems, $\mathrm{UK}$ ), using a compression test with a flat $\mathrm{P} / 75$ probe. The experimental graphs allowed to estimate hardness, resilience, cohesiveness, springiness and chewiness, as defined by Guiné et al. (2015).

For the sensory evaluation a panel of 26 non trained judges were used, for evaluation as a consumer panel. Although the judges were not trained for this type of product, they were experienced in making sensorial analysis. For the assessment of the sensorial profile the following attributes were analysed on a 5 point scale varying from 1 (least intense) to 5 (most intense): consistency, hardness, kiwi odour, kiwi taste, acidity, sweetness and homogeneity. Also a preference test was made to identify the sample preferred by the panellists.

\section{Results and Discussion}

\section{Chemical composition}

The results of the chemical analyses made are shown in Table 2, being the values and standard deviation calculated from 3 repetitions for each analysis in each sample.

The values obtained for moisture content were very similar in both cases, around $41 \%$, and the same was verified for the ash content, meaning that the amount of minerals in the bars was similar $(\sim 1.6 \%)$.

Table 2

\begin{tabular}{|c|c|c|}
\hline \multicolumn{3}{|c|}{ Results of the chemical analyses } \\
\hline Property & $\begin{array}{c}\text { Simple Kiwi } \\
\text { Bar (SKB) }\end{array}$ & $\begin{array}{c}\text { Kiwi bar } \\
\text { with walnut } \\
\text { (KBW) }\end{array}$ \\
\hline $\begin{array}{l}\text { Moisture content, } \\
\text { g } 100 \mathrm{~g}^{-1} \text { sample }\end{array}$ & $41.20 \pm 0.45$ & $40.77 \pm 1.02$ \\
\hline $\begin{array}{l}\text { Crude fibre, } \\
\text { g } 100 \mathrm{~g}^{-1} \text { sample }\end{array}$ & $5.70 \pm 0.14$ & $6.38 \pm 0.20$ \\
\hline 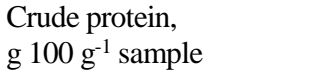 & $0.89 \pm 0.04$ & $1.16 \pm 0.03$ \\
\hline $\begin{array}{l}\text { Ash, } \\
\text { g } 100 g^{-1} \text { sample }\end{array}$ & $1.57 \pm 0.01$ & $1.67 \pm 0.02$ \\
\hline 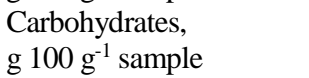 & $22.35 \pm 0.04$ & $24.90 \pm 0.02$ \\
\hline $\begin{array}{l}\text { Acidity, } \\
\text { mL citric acid } 100 \mathrm{~g}^{-1}\end{array}$ & $2.47 \pm 0.02$ & $2.34 \pm 0.02$ \\
\hline $\begin{array}{l}\text { Vitamin C, } \\
\text { mg ascorbic acid } 100 \mathrm{~g}^{-1}\end{array}$ & $23.60 \pm 0.40$ & $20.00 \pm 0.30$ \\
\hline
\end{tabular}

Regarding fibre, the bar with oat and walnut presented a slightly higher content $(6.38 \%)$ as compared to the simple kiwi bar $(5.70 \%)$, which had been expected since both the oat and walnut are foods rich in fibre (USDA, 2016). These results further indicate that both variations of the developed product are very rich in fibre, with much higher contents as compared to raw fruits such as kiwi $(3.0 \%)$, apple $(2.4 \%)$ or pear $(3.6 \%)$ (USDA, 2016).

The protein content was higher in the bar containing oat and walnut, which would be expected because these two products are much richer in protein as compared to kiwi (1.1\% in kiwi, $15.2 \%$ in walnut and $16.7 \%$ in oat) (USDA, 2016).
The carbohydrates were just slightly lower for the simple kiwi bar, but acidity was a little higher for this sample, due to the higher proportion of kiwi, which is naturally acidic. However, the vitamin $\mathrm{C}$ content was quite different, being higher in the simple kiwi bar, owing to the higher amount of kiwi pulp, which is much rich in this vitamin. The vitamin $\mathrm{C}$ content in raw kiwi is $92.7 \mathrm{mg} 100 \mathrm{~g}^{-1}$ (USDA, 2016).

Calculation of the caloric value for both bars is presented in Table 3. The results show that the simple kiwi bar is considerably less caloric (120 kcal $100 \mathrm{~g}^{-1}$ ) when compared with the kiwi bar with walnut $\left(\sim 182 \mathrm{kcal} 100 \mathrm{~g}^{-1}\right)$. For this certainly contributes the presence of walnut, which is a nut with a high caloric density (654 kcal $100 \mathrm{~g}^{-1}$ ), partially due to its elevated

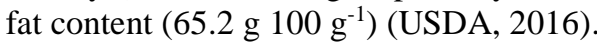

Table 3

\begin{tabular}{lccc}
\multicolumn{4}{c}{ Caloric value } \\
\hline \multirow{3}{*}{ Samples } & \multicolumn{3}{c}{ Energy } \\
\cline { 2 - 4 } & $\begin{array}{c}\text { kcal 100 g } \\
\text { sample }\end{array}$ & $\begin{array}{c}\text { kJ 100 g } \\
\text { sample }\end{array}$ & $\begin{array}{c}\text { kcal } \\
\text { portion }\end{array}$ \\
\hline $\begin{array}{l}\text { Simple Kiwi Bar } \\
\text { (SKB) }\end{array}$ & 120.0 & 502.3 & 42.0 \\
$\begin{array}{l}\text { Kiwi bar with } \\
\text { walnut } \\
\text { (KBW) }\end{array}$ & 181.8 & 761.0 & 63.6 \\
${ }^{*}$ 1 portion =35 g & & & \\
Colour & & & \\
\hline
\end{tabular}

The values of the Cartesian colour coordinates are shown in Table 4, being the values and standard deviation calculated from 40 measurements in each sample.

The lightness was equal in both samples, with values around 42 , corresponding to slightly dark samples. The value of $\mathrm{L}^{*}$ varies between 0 for black and 100 for white (Guiné, Barroca, 2014).

The opposing colour coordinate $\mathrm{a}^{*}$ ranges from green (for negative values) to red (positive) (Guiné, Barroca, 2014). Hence, while the simple kiwi bar showed a green coloration $\left(a^{*}=-2.12\right)$ the kiwi bar with walnut was just slightly red, with a positive value, but very close to zero $\left(a^{*}=0.39\right)$. This is due to the presence of the oat and walnut that make the colour tend to brown and diminish the predominance of the green colouration of the kiwi.

The other opposing colour coordinate, $b^{*}$, varies from blue (negative) to yellow (positive) (Guiné, Barroca, 2014). The values for both samples are similar (around 16), meaning that in both cases the intensity of yellow is relevant.

Table 4

Colour coordinates

\begin{tabular}{lcc}
\hline Colour coordinate & $\begin{array}{c}\text { Simple Kiwi } \\
\text { Bar (SKB) }\end{array}$ & $\begin{array}{c}\text { Kiwi bar } \\
\text { with walnut } \\
\text { (KBW) }\end{array}$ \\
\hline L $^{*}$ & $41.96 \pm 2.14$ & $41.81 \pm 3.38$ \\
$\mathrm{a}^{*}$ & $-2.12 \pm 0.70$ & $0.39 \pm 0.86$ \\
$\mathrm{~b}^{*}$ & $16.28 \pm 2.75$ & $15.55 \pm 2.24$ \\
\hline
\end{tabular}




\section{Texture}

The textural properties are presented in Table 5, being the values and standard deviation calculated from 8 determinations in each sample.

Hardness is the force required to compress a food between the teeth or between the tongue and mouth, and it comprises the force required to cause deformation. Cohesiveness represents the internal forces inside the food that maintain the sample as a whole, i.e., cohesive. Springiness or elasticity measures the ability to recover the shape after compression, and corresponds to the rate with which the product returns to the initial state after removal of the force which caused the deformation. Resilience is the energy used when applying a force to a material without occurring rupture, with or without any residual strain, and corresponds to an instant springiness. Adhesiveness represents the force required to remove the material that adheres to a specific surface, for example lips, palate or teeth. Finally, chewiness measures the energy required to disintegrate a food to such a state that it could be swallowed (Cruz et al., 2015; Guiné et al., 2014; 2015).

According to the results in Table 5, the kiwi bar with walnut was harder as compared with the simple kiwi bar ( $\sim 54 \mathrm{~N}$ and $\sim 59 \mathrm{~N}$, respectively), and also had higher chewiness $(\sim 34 \mathrm{~N}$ and $\sim 37 \mathrm{~N}$, respectively), which is expected since these two textural properties are intimately related.

Table 5

Textural properties

\begin{tabular}{lrr}
\hline Property & $\begin{array}{c}\text { Simple kiwi } \\
\text { bar (SKB) }\end{array}$ & $\begin{array}{c}\text { Kiwi bar } \\
\text { with walnut } \\
\text { (KBW) }\end{array}$ \\
\hline Hardness, N & $54.25 \pm 3.03$ & $59.15 \pm 3.53$ \\
Cohesiveness & $0.78 \pm 0.03$ & $0.73 \pm 0.04$ \\
Springiness, \% & $81.93 \pm 1.68$ & $77.25 \pm 1.95$ \\
Resilience, \% & $36.57 \pm 1.57$ & $36.05 \pm 2.76$ \\
Adhesiveness, N.s & $-0.80 \pm 0.08$ & $-0.62 \pm 0.08$ \\
Chewiness, N & $33.83 \pm 2.13$ & $37.15 \pm 1.57$ \\
\hline
\end{tabular}

Cohesiveness, on the other hand, was lower for the sample containing walnut and oat (0.73 against 0.78$)$, because the linking of the ingredients was poorer due to the presence of these components. Hence the simple kiwi bar showed a higher capacity of maintaining integrity.

Springiness was higher for the simple kiwi bar $(82 \%$ against $77 \%$ ), because the bar containing only kiwi was more elastic as compared with the bar containing oat and walnut. Nevertheless, the results for resilience were practically equal in both variations of the product.

Adhesiveness was higher for the simple kiwi bar (higher absolute values) when compared to the kiwi bar with walnut (-0.80 and $-0.62 \mathrm{~N} \cdot \mathrm{s}$, respectively).

\section{Sensorial evaluation}

The sensorial profiles for both samples are shown in Figure 1, resulting from the mean values for each attribute evaluated by the 26 panellists.

The simple kiwi bar was evaluated by the panellists as more homogeneous, sweeter, softer, with more intense odour and taste to kiwi and slightly more acidic. On the other hand, regarding consistency, both samples were perceived equally.

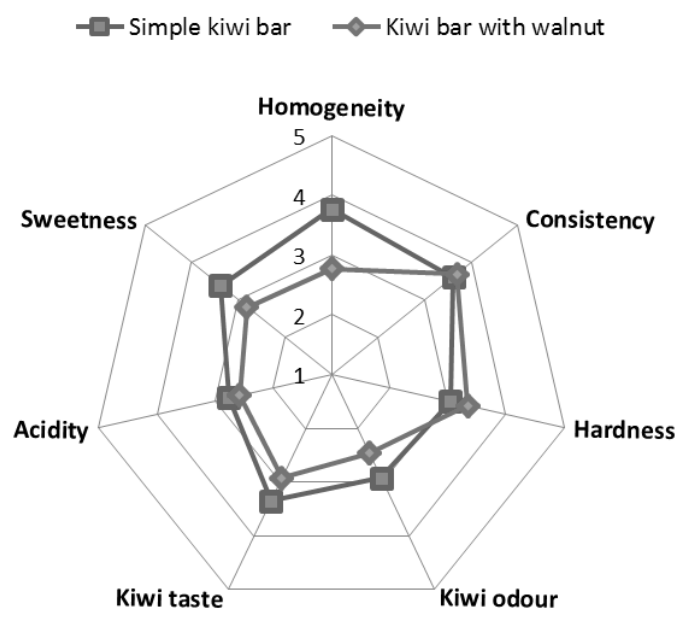

Figure 1. Sensorial profiles of the kiwi bars

The preference test indicated that 19 of the 26 members of the panel preferred the simple kiwi bar, corresponding to $73 \%$. Hence, it was concluded that from the two variations of the product developed the simple kiwi bar has more potential to be accepted by the consumers when compared to the kiwi bar with walnut.

\section{Conclusions}

In the formulation of bars made from kiwi, it was possible to see that the gelling agent used, as well as the amounts of all ingredients, greatly interfered with the characteristics of the final product. In view of this, it was necessary to test different formulations and try various types and amounts of gellants until obtaining the desired product.

In the study of physicochemical evaluation, it was possible to perceive that the simple kiwi bar had lower caloric value and was less rich in fibre, protein, ash and carbohydrates as compared to the kiwi bar with walnut. On the contrary, acidity was higher and so was the content of vitamin C.

Regarding colour, the differences between both bars were essentially in the coordinate $\mathrm{a}^{*}$, so that the simple kiwi bar showed a green colouration while the kiwi bar with walnut showed predominance of red. Lightness and yellowness were similar in both bars.

In what concerned the textural properties, the simple kiwi bar was softer, more elastic and more adhesive as compared to the bar with walnut and oat.

Sensory evaluation allowed establishing the sensorial profiles of both samples tested, with the simple kiwi bar showing higher average scores for the majority of the attributes evaluated: homogeneity, sweetness, acidity, kiwi taste, and kiwi odour. Furthermore, the preference test clearly indicated that the simple kiwi bar was the most appreciated of the two varieties of the product developed. 


\section{Acknowledgment}

This work was financed by FCT (Portuguese Foundation for Science and Technology), under project UID/Multi/04016/2016. Furthermore we would like to thank the Polytechnic Institute of Viseu and CI\&DETS for their support.

\section{References}

1. AOAC. (2012) Official Methods of Analysis of AOAC International (19th Edition). Arligton, VA: Association of Official Analytical Chemists.

2. Cruz A. C., Guiné R. P. F., Gonçalves J. C. (2015) Drying kinetics and product quality for convective drying of apples (cvs. Golden Delicious and Granny Smith). International Journal of Fruit Science, Vol. 15(1), p. 54-78.

3. Guin R. P. F., Almeida I. C., Correia A. C., Gonçalves F.J. (2015) Evaluation of the physical, chemical and sensory properties of raisins produced from grapes of the cultivar Crimson. Journal of Food Measurement and Characterization, Vol. 9 (3), p. 337-346.

4. Guiné R. P. F., Barroca M. J. (2014) Quantification of browning kinetics and colour change for quince (Cydonia oblonga Mill.) exposed to atmospheric conditions. Agricultural Engineering International: CIGR Journal, Vol. 16 (4), p. 285-298.

5. Guiné R.P.F., Henriques F., Barroca M. J. (2014) Influence of drying treatments on the physical and chemical properties of cucumber. Journal of
Food Measurement and Characterization, Vol. 8 (3), p. $195-206$.

6. Le T. M., Knulst A. C. (2015) Kiwifruit allergy across Europe. Revue Française d'Allergologie, Vol. 55 (7), p. $470-473$.

7. Lu Y., Chen Z., Kang T., Zhang X., Bellarby J., Zhou J. (2016) Land-use changes from arable crop to kiwiorchard increased nutrient surpluses and accumulation in soils. Agriculture, Ecosystems \& Environment, Vol. 223, p. 270-277.

8. Park Y.-S., Namiesnik J., Vearasilp K., Leontowicz H., Leontowicz M., Barasch D., Nemirovsk, A., Trakhtenberg S., Gorinstein S. (2014) Bioactive compounds and the antioxidant capacity in new kiwi fruit cultivars. Food Chemistry, Vol. 165, p. 354-361.

9. Sharma R., Oberoi H. S., Dhillon G. S. (2016) Chapter 2 Fruit and vegetable processing waste: renewable feed stocks for enzyme production. In: Agro-Industrial Wastes as Feedstock for Enzyme Production. G. S. Dhillon, S. Kaur (eds). San Diego: Academic Press, p. 23-59.

10. Soquetta M. B., Stefanello F. S., Huerta K. da M., Monteiro S. S., da Rosa C. S., Terra N. N. (2016) Characterization of physiochemical and microbiological properties, and bioactive compounds, of flour made from the skin and bagasse of kiwi fruit (Actinidia deliciosa). Food Chemistry, Vol. 199, p. 471-478.

11. USDA. (2016). USDA Food Composition Databases. United States Departmentnof Agriculture, Agricultural Research Service [accessed on 23.12.2016.]. Available at: https://ndb.nal.usda.gov/ndb/search. 